\title{
Emphasizing Qualitative Study
}

Qualitative research is a method of inquiry appropriated in many different academic disciplines, traditionally in the social sciences, but also in market research and further contexts. ${ }^{1}$ Its use has been increased in the medical education research and hospital based study too. It aims to gather an in-depth understanding of human behavior and the reasons that govern such behavior. The qualitative method investigates the why and how of decision making, not just what, where, when. Hence, smaller but focused samples are more often needed, rather than large samples.

The advantages of qualitative studies is to produces more in-depth, comprehensive information. It uses subjective information and participant observation to describe the context, or natural setting, of the variables under consideration, as well as the interactions of the different variables in the context. It seeks a wide understanding of the entire situation. The disadvantages includes; the very subjectivity of the inquiry leads to difficulties in establishing the reliability and validity of the approaches and information. It is very difficult to prevent or detect researcher induced bias. Its scope is limited due to the in-depth, comprehensive data gathering approaches required. ${ }^{2}$

There has been increasing voices about the importance of qualitative studys. ${ }^{3}$ However; most of the researchers and academicians in our country are still fascinated about the quantitative study, only. This can be evident by the article submitted and published by the medical journals of Nepal. The MEDLINE search for the term qualitative study has shown more than seventy three thousand results. That doesn't mean all articles that has been indexed are about it but some or other way they contains the qualitative study in the text. $^{4}$

There was a time when researchers, academicians used to think that qualitative study is not a study. But they realized it was wrong to have such concept and those are the people who are advocating for more qualitative study in the country. They realized their misconception much later in their lives. This is not only true in our region but in the world too.

Many leading journals began to publish qualitative research articles by the end of $1970 \mathrm{~s}^{5}$ and several new journals emerged which published only qualitative research studies and articles about qualitative research methods. ${ }^{6}$ In the 1980 s and 1990s, the new qualitative research journals became more multidisciplinary in focus moving beyond qualitative research's traditional disciplinary roots of anthropology, sociology, and philosophy. ${ }^{6}$ The new millennium saw a dramatic increase in the number of journals specializing in qualitative research with at least one new qualitative research journal being launched each year.

Qualitative methods produce information only on the particular cases studied, and any more general conclusions are only hypotheses. Quantitative methods can be used to verify which of such hypotheses are true. We should not think that quantitative studies are applied everywhere; instead qualitative study has also got its own existence and importance. We should start doing qualitative research in hospital to improve its services, medical colleges for quality medical education, community for better health services and many more. 


\section{REFERENCES:}

1. Denzin NK, Lincoln YS, editors. The Sage Handbook of Qualitative Research. 3rd ed. Thousand Oaks, CA: Sage; 2005. p. 1-33. ISBN 0-7619-2757-3

2. Key JP. Moduel R14 qualitative research [Online]. [cited 2010 Sep 20]; Available from: URL:http:// www.okstate.edu/ag/agedcm4h/academic/aged5980a/5980/newpage21.htm

3. Cauvin LR. Importance of Qualitative Research [Online]. 2005 Aug 16 [cited 2010 Jul 21]; Available from: URL:http:/ /blog.cauvin.org/2005/08/importance-of-qualitative-research.html

4. U.S. National Library of Medicine National Institutes of Health. PubMed [Online]. [cited 2010 Sep 21]; Available from: URL: http://www.ncbi.nlm.nih.gov/pubmed/

5. DR Loske, Cahil SE. Publishing qualitative manuscripts: Lessons learned. In Seale C, Gobo G, Gubrium JF, Silverman D, editors. Qualitative Research Practice: Concise Paperback Edition. London: Sage; 2007. p. 491-506. ISBN 978-1-7619-4776-9.

6. Denzin NK, Lincoln YS. Introduction: The discipline and practice of qualitative research. In Denzin NK, Lincoln YS, editors. The Sage Handbook of Qualitative Research. 3rd ed. Thousand Oaks, CA: Sage; 2005. p. 1-33. ISBN 0-7619-2757-3 